\title{
The Next Twenty Years: Predicting and Preparing for the Future Cancer Landscape in Sub-Saharan Africa
}

\author{
Prévoir et se préparer aux nouvelles caractéristiques du cancer en Afrique Subsaharienne \\ pour les vingt prochaines années
}

\section{T.R. Rebbeck}

C) Springer-Verlag France 2014

\section{What Will the Leading African Cancers Be in 2035? Can They Be Prevented?}

Cancer incidence and mortality will increase over the next 20 years. The age-standardized numbers of new cancer cases (incidence) or death (mortality) per 100000 are shown in Table 1 and the predicted increases between 2015 and 2035 in Fig. 1. The numbers are based on Globocan predictions for the WHO-AFRO region (i.e., Sub-Saharan Africa; SSA), and account for the anticipated demographic changes (e.g., population aging) during this period [1].

In 2015, Globocan predicts that approximately 286530 men and 412912 women will be diagnosed with cancer; 221131 men and 270472 of women are predicted to die from cancer (Table 1). By 2035, cancer incidence is predicted to increase by $83-87 \%$ and mortality will increase by $84-89 \%$. All of the leading cancers in both men and women are predicted to increase in incidence and mortality by 2035 , with most cancers exhibiting an approximate doubling between 2015 and 2035. These figures are based on limited population-based registry data in SSA, and the future predictions are based on models that do not account for many factors that could affect future rates. However, it is clear that incidence and mortality from cancer will be a growing public health problem in SSA.

Of the most common cancers (Table 1), many deaths could be avoided if screening and early detection were available. These include cervical cancer, which can be prevented by vaccination or if detected early by pap smear or visual inspection with acetic acid. These technologies exist in SSA and can be implemented in low resource settings [2]. Similarly, liver

T.R. Rebbeck $(\bowtie)$

Department of Biostatistics and Epidemiology and Abramson Cancer Center, University of Pennsylvania Perelman

School of Medicine, 217 Blockley Hall, 423 Guardian Drive, Philadelphia, PA 19104-6021, USA

e-mail : rebbeck@upenn.edu cancer could be prevented by hepatitis B vaccination [3], and smoking eradication programs could prevent lung cancer [4]. These are by no means easy solutions to implement, but they are possible even in low resource settings. Other screening and early detection tools may require much more resourceand training-intensive strategies, including mammography for breast cancer and colonoscopy for colorectal cancer. Prevention strategies for prostate cancer, the most common cancer in SSA men, are fraught with difficulties of poor screening properties of prostate-specific antigen (PSA) [5]. Implementation of PSA screening in SSA will require careful consideration and additional data before implementation.

\section{What Factors Will Influence Changes in Cancer Rates by 2030?}

Numerous factors will contribute to changes in cancer risks and mortality in the coming decades. These include changes in demographics and life expectancy, common causes of death, and cancer risk factors.

\section{Increasing Lifespan}

Cancer in general tends to be a disease of aging. As populations age, more cancers will be diagnosed. It is likely that a greater proportion of the population will fall into the range of risk for many common cancers by 2035. As shown in Fig. 2, life expectancy in 1990 at birth in the WHO-AFRO region was 51.5 in women and 47.8 in men [6]. Life expectancy did not change between 1990 and 2000, but began to increase in 2011 to 57.6 in women and 55.0 among men. Trends toward longer life spans are likely to continue.

\section{Changes in Causes of Death}

Based on WHO Global Health Observatory Data Repository (Table 2) [6,7], all-cause mortality in SSA is predicted to 


\begin{tabular}{|c|c|c|c|c|c|c|c|}
\hline \multirow[t]{2}{*}{ Rank } & \multirow[t]{2}{*}{ Site } & \multicolumn{3}{|c|}{ Incidence } & \multicolumn{3}{|c|}{ Mortality } \\
\hline & & 2015 & 2035 & $\%$ Increase & 2015 & 2035 & $\%$ Increase \\
\hline Men & All Sites ${ }^{a}$ & 286530 & 535094 & 87 & 221131 & 417465 & 89 \\
\hline 1 & Prostate & 51689 & 107170 & 107 & 37486 & 76321 & 104 \\
\hline 2 & Liver & 24791 & 50684 & 104 & 23758 & 48419 & 104 \\
\hline 3 & Kaposi sarcoma & 23100 & 44205 & 91 & 15832 & 31360 & 98 \\
\hline 4 & Colorectum & 15505 & 32203 & 108 & 11315 & 23460 & 107 \\
\hline 5 & Non-Hodgkin lymphoma & 15036 & 28501 & 90 & 10852 & 21116 & 95 \\
\hline 6 & Esophagus & 13695 & 28784 & 110 & 12514 & 26259 & 110 \\
\hline 7 & Lung & 11786 & 24877 & 111 & 10522 & 22186 & 111 \\
\hline 8 & Stomach & 10496 & 21969 & 109 & 9556 & 19934 & 109 \\
\hline 9 & Leukemia & 8782 & 16732 & 91 & 7804 & 15147 & 94 \\
\hline 10 & Lip, oral cavity & 8009 & 16520 & 106 & 5026 & 10480 & 109 \\
\hline Women & All Sites ${ }^{a}$ & 412912 & 755334 & 83 & 270472 & 498803 & 84 \\
\hline 1 & Cervix uteri & 92340 & 185764 & 101 & 56601 & 114406 & 102 \\
\hline 2 & Breast & 99760 & 199873 & 100 & 49061 & 97917 & 100 \\
\hline 3 & Liver & 14032 & 28186 & 101 & 13403 & 26903 & 101 \\
\hline 4 & Colorectum & 15037 & 30242 & 101 & 11029 & 22220 & 101 \\
\hline 5 & Ovary & 13034 & 25918 & 99 & 9758 & 19621 & 101 \\
\hline 6 & Esophagus & 9767 & 19783 & 103 & 8981 & 18825 & 110 \\
\hline 7 & Kaposi sarcoma & 13313 & 24806 & 86 & 8920 & 17102 & 92 \\
\hline 8 & Stomach & 8614 & 17408 & 102 & 8033 & 16243 & 102 \\
\hline 9 & Non-Hodgkin lymphoma & 11232 & 20985 & 87 & 8399 & 15987 & 90 \\
\hline 10 & Leukemia & 7186 & 13714 & 91 & 6496 & 12582 & 94 \\
\hline
\end{tabular}

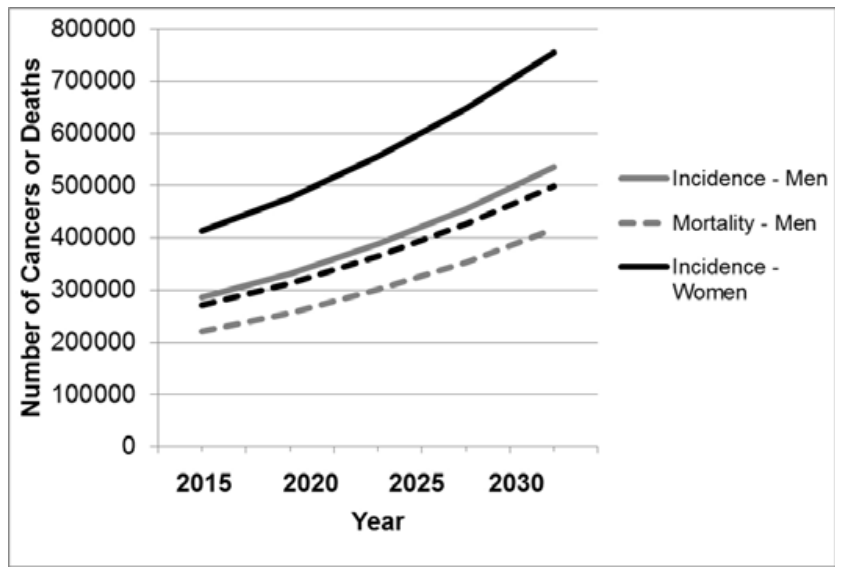

Fig. 1 Age-adjusted incidence and mortality for men and women in the WHO-AFRO region. 2015-2035

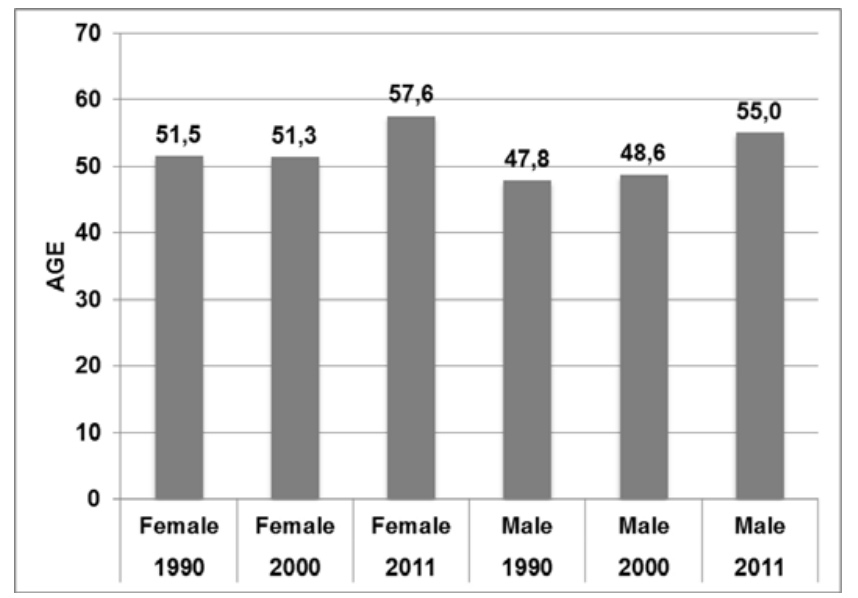

Fig. 2 Life expectancy at birth by gender, WHO-AFRO region. Source: Global Health Observatory, WHO, 2014 
Table 2 Causes of mortality in WHO-AFRO region, per 100000 population; all ages, all causes, communicable vs. noncommunicable, and top 20 causes in 2015 and 2030.

\begin{tabular}{|c|c|c|c|}
\hline Cause & 2015 & Cause & 2030 \\
\hline All Causes & 1044.1 & All Causes & 918.8 \\
\hline Communicable \& other Group I & 601.9 & Communicable \& other Group I & 425.9 \\
\hline Non-communicable diseases & 344.6 & Non-communicable diseases & 390.1 \\
\hline Infectious and parasitic diseases & 324.9 & Infectious and parasitic diseases & 228.5 \\
\hline Cardiovascular diseases & 125.0 & Cardiovascular diseases & 149.9 \\
\hline Respiratory infections & 119.9 & Injuries & 102.8 \\
\hline Lower respiratory infections & 119.6 & HIV/AIDS & 98.9 \\
\hline HIV/AIDS & 118.7 & Respiratory infections & 88.6 \\
\hline Neonatal conditions & 100.9 & Lower respiratory infections & 88.3 \\
\hline Injuries & 97.6 & Unintentional injuries & 83.0 \\
\hline Unintentional injuries & 75.9 & Neonatal conditions & 74.5 \\
\hline Diarrheal diseases & 73.6 & Malignant neoplasms & 73.7 \\
\hline Malignant neoplasms & 55.2 & Stroke & 65.3 \\
\hline Stroke & 54.5 & Ischemic heart disease & 48.4 \\
\hline Parasitic and vector diseases & 48.3 & Diarrheal diseases & 42.1 \\
\hline Preterm birth complications & 46.3 & Digestive diseases & 37.7 \\
\hline Malaria & 41.2 & Road injury & 37.2 \\
\hline Digestive diseases & 40.4 & Parasitic and vector diseases & 35.7 \\
\hline Nutritional deficiencies & 39.8 & Preterm birth complications & 34.2 \\
\hline Ischemic heart disease & 39.8 & Malaria & 31.6 \\
\hline Birth asphyxia and birth trauma & 35.4 & Diabetes mellitus & 29.8 \\
\hline Protein-energy malnutrition & 34.6 & Respiratory diseases & 27.2 \\
\hline Respiratory diseases & 24.9 & Birth asphyxia and birth trauma & 26.2 \\
\hline
\end{tabular}

drop in the coming decades. Communicable diseases will remain the most important causes of death, but the number of deaths due to communicable diseases will drop, and noncommunicable diseases will comprise a larger proportion of deaths. Deaths from major infectious diseases including HIV/AIDS, respiratory infections, diarrheal diseases, parasitic and vector diseases, and malaria will drop. Deaths due to some non-communicable causes including infant mortality will also drop. In contrast, the proportion of deaths attributable to chronic diseases will grow. These include cardiovascular disease, stroke, and cancer. Cancer will grow from 55.2 deaths per 100000 individuals in the WHO-AFRO region in 2015 to 73.7 per 100000 in 2030. This represents an increase in cancer-specific deaths of $34 \%$ in 15 years.

\section{Changes in Cancer Risk Factors}

Trends in lifestyle, exposures, and risk factors are also likely to impact the pattern of SSA cancer risk in the coming decades. One metric of change in lifestyle that is also correlated with the risk of some cancers is obesity. As shown in Fig. 3, the proportion of men and women who are overweight or obese (body mass index $(\mathrm{BMI})>25)$ in SSA grew between 2002 and 2010. In this relatively short time frame, numerous countries moved from low rates of overweight/obese $(<25 \%)$, to moderate rates $(25-50 \%)$, to high rates $(>50 \%)$ in both men and women. For example, over $50 \%$ of South African men were overweight or obese in 2002. By 2010, over half of men in Botswana and Cameroon were also overweight/obese. There are a growing number of SSA countries in which over $50 \%$ of women are overweight/obese ( 8 in 2002 to 13 in 2010). These trends reflect changes that may confer higher cancer risks for obesity-related cancers, and for other cancers associated with physical activity, diet, and other lifestyle factors.

\section{How Can We Prepare for 2035?}

Numerous statements provide guidance to those who need to develop effective cancer prevention and control programs in SSA [7-9]. Table 3 summarizes steps toward this goal. These include creation of an evidence base about the cancer burden in a population, including cancer types, incidence, mortality, and prevalence. Currently, this information is 

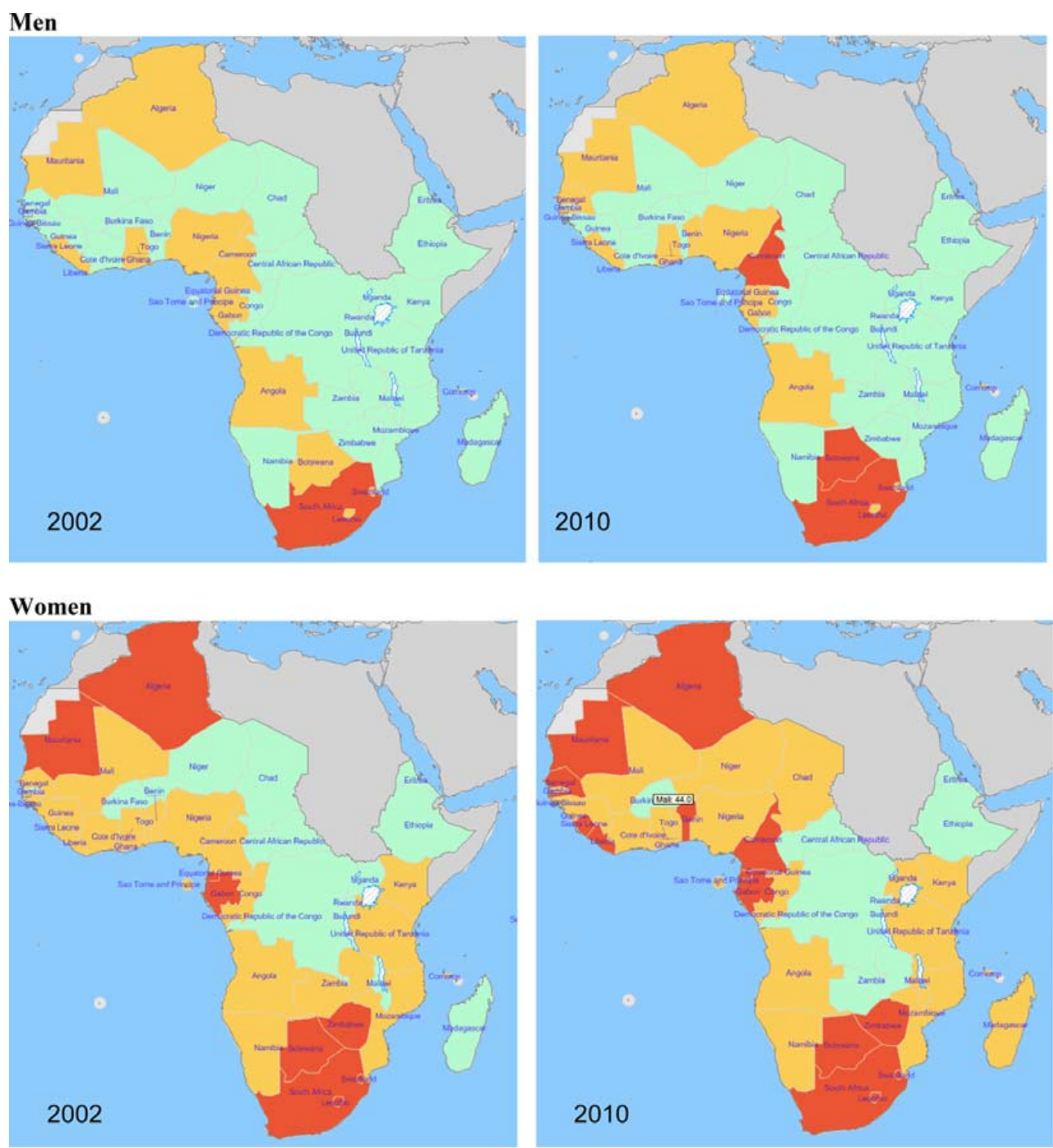

Percent of Population Overweight or Obese $(\mathrm{BMI}>25)$ :

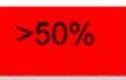

$25-50 \%$

$<25 \%$

Fig. 3 Percent of men and women who are overweight or obese (BMI $>25$ ), by country, 2002 and 2010 . $<25 \%$ (Green), 25-50\% (Orange), $>50 \%$ (Red)

sub-optimal in SSA. High quality information about the cancer burden will provide the foundation around which current and future needs for cancer control are determined.

Situational analyses are required to provide information about the current state of preparedness for cancer-related activities. This assessment includes research, clinical, and staffing capacity, as well as the potential for these domains to address identified needs. The specific goals for these domains depend on the current state of the system, as well as knowledge about the gaps between the current system and the future needs and goals.

Once sufficient evidence has been collected to assess needs, a cancer plan can be created. This plan may be developed on the local, regional, or national levels, and should lay out a sustainable system for the prevention and control of cancer. This plan should be developed in conjunction with key stakeholders, including advocates, policy-makers, the clinical community, and those responsible for funding. Protocols, success metrics, and evaluation methods should be developed and implemented. In some cases, research should be undertaken to determine the optimal means of implementation. Finally, the implemented plan requires monitoring and evaluation, including assessment of cost-effectiveness of the implemented strategies.

Given the growing cancer burden in SSA and the anticipated needs for cancer prevention and control in the coming decades, these steps cannot wait: serious and expedient action to address these concerns is needed. 
Table 3 Framework for the development, implementation, and monitoring of effective cancer control strategies.

\begin{tabular}{|c|c|c|}
\hline Step & Goal & Possible Tasks \\
\hline Create evidence base & $\begin{array}{l}\text { - Obtain accurate tumor registry data } \cdot \text { Assess } \\
\text { present and future cancer risks } \cdot \text { Assess } \\
\text { prevention and treatment needs }\end{array}$ & $\begin{array}{l}\text { - Link with tumor registry systems and experts } \\
\text { Situational or SWOT-type analysis }\end{array}$ \\
\hline \multicolumn{3}{|l|}{$\downarrow$} \\
\hline $\begin{array}{l}\text { Assess research needs } \\
\text { and capacity } \\
\downarrow\end{array}$ & $\begin{array}{l}\text { - Identify research domains that are needed } \\
\text { to address cancer needs in evidence base }\end{array}$ & $\begin{array}{l}\text { - Situational or SWOT-type analysis } \bullet \text { Needs } \\
\text { assessment }\end{array}$ \\
\hline $\begin{array}{l}\text { Assess prevention } \\
\text { and treatment needs } \\
\text { and capacity } \\
\downarrow\end{array}$ & $\begin{array}{l}\text { - Identify clinical resources and technologies } \\
\text { Identify infrastructure gaps }\end{array}$ & $\begin{array}{l}\text { - Situational or SWOT-type analysis } \bullet \text { Needs } \\
\text { assessment }\end{array}$ \\
\hline $\begin{array}{l}\text { Assess staffing and training } \\
\text { needs and capacity }\end{array}$ & $\begin{array}{l}\text { Quantify existing clinical, research, } \\
\text { and advocacy infrastructure and staffing } \\
\text { Evaluate training programs and their potential } \\
\text { to meet current and future staffing needs }\end{array}$ & $\begin{array}{l}\text { - Situational or SWOT-type analysis } \cdot \text { Needs } \\
\text { assessment }\end{array}$ \\
\hline \multicolumn{3}{|l|}{$\downarrow$} \\
\hline $\begin{array}{l}\text { Develop local, regional, } \\
\text { or national cancer plan }\end{array}$ & $\begin{array}{l}\text { - Create a sustainable system for cancer } \\
\text { prevention, control, treatment, and advocacy } \\
\text { to meet the cancer needs of the population }\end{array}$ & $\begin{array}{l}\text { - Create protocols, metrics, and evaluation } \\
\text { methods for plan components } \cdot \text { Interact with } \\
\text { stakeholders } \cdot \text { Develop and implement timeline }\end{array}$ \\
\hline \multicolumn{3}{|l|}{$\downarrow$} \\
\hline Implement cancer plan & $\begin{array}{l}\text { - Undertake implementation and dissemination } \\
\text { research to ensure the strategy works } \\
\text { in the population - Perform cost-effectiveness } \\
\text { analysis to assess feasibility of cancer plan }\end{array}$ & $\begin{array}{l}\text { - Develop necessary infrastructure and protocols } \\
\text { - Educate the public, policy-makers, clinicians, } \\
\text { and educators about the need for cancer activities }\end{array}$ \\
\hline \multicolumn{3}{|c|}{$x^{3}$} \\
\hline Monitor cancer plan & $\begin{array}{l}\text { - Assess impact of cancer plan } \cdot \text { Modify cancer } \\
\text { plan as needed }\end{array}$ & $\begin{array}{l}\text { - Regular evaluation of plan and metrics } \\
\text { of success }\end{array}$ \\
\hline
\end{tabular}

Conflict of interest: T.R. Rebbeck do not have any conflict of interest to declare.

\section{References}

1. Ferlay J, Soerjomataram I, Ervik M, et al (2013) GLOBOCAN 2012 v1.0, Cancer Incidence and Mortality Worldwide: IARC CancerBase $\mathrm{n}^{\mathrm{o}} 11$ [Internet]. Lyon, International Agency for Research on Cancer

2. Sankaranarayanan R, Anorlu R, Sangwa-Lugoma G, et al (2013) Infrastructure requirements for human papillomavirus vaccination and cervical cancer screening in sub-Saharan Africa. Vaccine 31: F47-F52

3. Chang MH (2014) Prevention of hepatitis B virus infection and liver cancer. Recent Results. Cancer Res 193:75-95
4. Abdullah AS, Stillman FA, Yang L, et al (2014) Tobacco use and smoking cessation practices among physicians in developing countries: a literature review (1987-2010). Int J Environ Res Public Health 11:429-55

5. Moyer VA, Force USPST (2012) Screening for prostate cancer: US Preventive Services Task Force recommendation statement. Ann Intern Med 157:120-34

6. Global Health Observatory (GHO) 2012 Report

7. Stefan DC, Elzawawy AM, Khaled HM, et al (2013) Developing cancer control plans in Africa: examples from five countries. Lancet Oncol 14:e189-e95

8. Morhason-Bello IO, Odedina F, Rebbeck TR, et al (2013) Challenges and opportunities in cancer control in Africa: a perspective from the African Organisation for Research and Training in Cancer. Lancet Oncol 14:e142-e51

9. Adewole I, Martin DN, Williams MJ, et al (2014) Building capacity for sustainable research programmes for cancer in Africa. Nat Rev Clin Oncol (in press) 